\title{
Is Interstitial Cells of Cajal-opathy Present in Gastroparesis?
}

\author{
Mohammad Bashashati and Richard W McCallum* \\ Department of Internal Medicine, Texas Tech University Health Sciences Center, El Paso, TX, USA
}

Gastroparesis (GP), defined as delayed gastric emptying in the absence of any mechanical obstruction, is a challenging clinical condition, mainly because of limited treatment options. Studies in animal models of delayed gastric emptying as well as patients with gastroparesis revealed depletion or ultrastructural changes of interstitial cells of Cajal (ICC) in the gastric tissue, recently termed ICC-opathy. ICC are the pacemakers of the gastrointestinal tract and are involved in the transmission of the neuronal signaling to the smooth muscles. Therefore, lack of ICC could be one explanation of delayed gastric emptying in gastroparetic patients. How frequently ICC changes are observed in gastroparesis is not yet clear. In this review, the data on gastric ICC counts and morphology in animal models and patients with gastroparesis are discussed.

(J Neurogastroenterol Motil 2015;21:486-493)

\section{Key Words}

Gastroparesis; Interstitial cells of Cajal; Physiopathology

\section{Introduction}

Gastroparesis (GP), affecting up to 10 million individuals in the United States (US), is a relatively common gastrointestinal (GI) motility disorder and is defined as delayed gastric emptying without any mechanical obstruction. GP presents with upper GI symptoms such as nausea, vomiting, early satiety, postprandial fullness, bloating, and abdominal pain. The etiology of GP in the majority of cases are idiopathic (IP-GP), while many others are diabetic (DM-GP). ${ }^{1}$ Based on the limited number of community or population studies, the age adjusted prevalence of IP-GP is
37.8 and 9.6 in 100000 women and men, respectively. ${ }^{2}$ The average cumulative incidence of GP during a 10 year period was $5.2 \%$ in type $1 \mathrm{DM}, 1 \%$ in type $2 \mathrm{DM}$, and $0.2 \%$ in the controls. ${ }^{3}$ Another study in a more representative population indicated a higher prevalence for DM-GP, estimating that approximately 165000 patients with type $1 \mathrm{DM}$ (14\% of US patients with type $1 \mathrm{DM}$ ) and 2.1 million patients with type $2 \mathrm{DM}(9.4 \%)$ were actually seeking treatment for their GP symptoms. ${ }^{4}$

Patients with GP suffer from nutritional deficiencies and metabolic consequences as well as impaired social activities and quality of life. Hospitalizations due to GP increased by 2.4 fold in the US between 1995 and 2004. Moreover, work absenteeism,

Received: May 5, 2015 Revised: July 22, 2015 Accepted: August 7, 2015

(c) This is an Open Access article distributed under the terms of the Creative Commons Attribution Non-Commercial License (http://creativecommons. org/licenses/by-nc/4.0) which permits unrestricted non-commercial use, distribution, and reproduction in any medium, provided the original work is properly cited.

*Correspondence: Richard W McCallum, MD, FACP, FRACP (AUST), FACG, AGAF Department of Internal Medicine, Center for Neurogastroenterology and GI Motility, 4800 Alberta Avenue, El Paso, TX 79905, USA
Tel: +1-915-215-5218, Fax: +1-915-545-6634, E-mail: richard.mccallum@ttuhsc.edu

Financial support: None.

Conflicts of interest: None.

Author contributions: Mohammad Bashashati and Richard W McCallum reviewed the literature, interpreted available data and drafted the manuscript.

ORCID: Mohammad Bashashati, http://orcid.org/0000-0002-3237-4715; Richard W McCallum, http://orcid.org/0000-0002-6652-8049. 
high unemployment rate and lower household income are variably associated with GP. ${ }^{5,6}$ Treatment of GP is based on alleviating symptoms, enhancing gastric emptying, correcting nutritional abnormalities and targeting the underlying causes, although it is usually challenging and often suboptimal. ${ }^{1}$ Therefore, finding new drug and device targets for the treatment of this chronic disorder is a research priority in the field of GI motility disorders.

Identifying disease biomarkers may help us in developing better strategies for the diagnosis and management of the gastroparetic patients. These biomarkers could provide a rationale for an individualized approach which could be linked to the treatment outcome and prognosis in these patients. A potential biomarker in this area is the interstitial cells of Cajal (ICC).

ICC are mesenchymal cells acting as the pacemakers for the generation of slow waves in the GI tract (Fig. 1). Their electrical activity defines the frequency of the rhythmic contraction. ICC are involved in GI motor activities, as conduits for muscular innervation and are possibly transmitters of sensory innervation in the GI tract. ICC are distributed throughout the GI tract from the esophagus to the internal anal sphincter and within different layers specifically submucosal (ICC-SM), myenteric plexus (ICC-MP), intramuscular (ICC-IM), and ICC deep muscular plexus (ICC-DMP). Two major distributions of ICC which determine gastric motility are: (1) ICC-IM and (2) ICC-MP. ${ }^{7-10}$

Both ICC count and morphology are important in gastric electrophysiology and as a biomarker for GI motility disorders. ICC express C-Kit, a receptor tyrosine kinase, which is necessary for the development and maintenance of ICC phenotype. There- fore, the population and morphology of ICC can be studied by ICC markers including C-Kit (Fig.1) and anoctamin-1 (ANO1). ${ }^{7,9,11}$

Loss of ICC, identified by the loss of C-Kit or ANO1 immunostaining, has been recognized in different GI disorders such as slow transit constipation ${ }^{12}$ and inflammatory bowel disease, ${ }^{13,14}$ and there is a relatively substantial and growing body of literature on the loss or altered morphology of ICC in GP. ${ }^{15-18}$

In order to understand the role of ICC in the pathophysiology of GP, it is crucial to know the normal distribution and population as well as the structure of these cells in the stomach. Therefore, the aim of this systematic review was to explore research articles on the distribution, population and morphology of ICC in the pathogenesis of GP.

\section{Methodology}

To identify clinical and basic studies on ICC in GP or animal models of GP, PubMed was systematically searched in February 2015 with the search terms shown in Table 1.

In total, 453 studies were retrieved for the evaluation. The articles were examined through reviewing their titles and abstracts. Full-text of the relevant abstracts and their list of references were fully evaluated. Studies which compared the population of ICC in the gastric tissue of gastroparetic patients or animal models of delayed gastric emptying compared to controls were included and reviewed. In addition to this, we examined studies on the structure (or ultrastructure) of ICC in GP. Studies which were not in English were excluded.

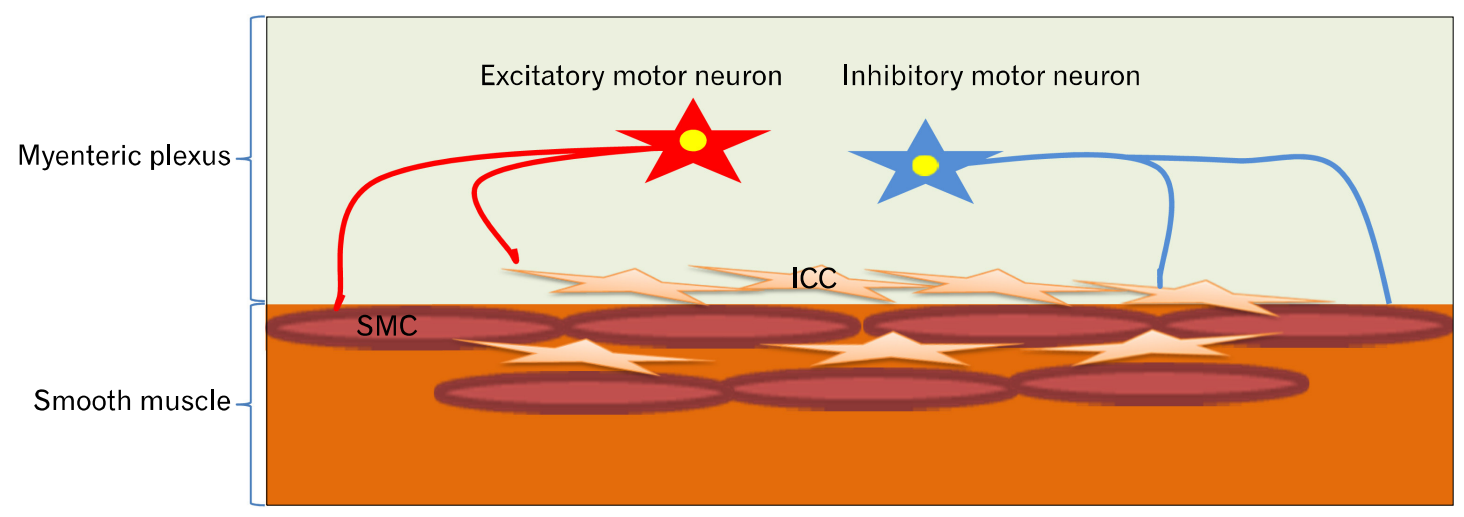

Figure 1. Interstitial cells of Cajal (ICC) are the pacemakers for the generation of slow waves in the gastrointestinal tract. Enteric nervous system innervates both ICC and smooth muscle cells (SMC), and ICC are also conduits for muscular innervation. 
Table 1. Search Strategy in PubMed for Interstitial Cell of Cajal and Gastroparesis

\begin{tabular}{lr}
\hline \multicolumn{1}{c}{ Search terms } & Items found \\
\hline ([Interstitial cells of Cajal] OR [Cajal interstitial cells] OR [Interstitial cell of Cajal] OR [Cajal interstitial cell]) AND & 453 \\
$\quad$ ([stomach] OR [gastric] OR [gastroparesis] OR [gastric emptying]) & 331693 \\
(stomach) OR (gastric) OR (gastroparesis) OR (gastric emptying) & 1857 \\
(Interstitial cells of Cajal) OR (Cajal interstitial cells) OR (Interstitial cell of Cajal) OR (Cajal interstitial cell) & 12728 \\
gastric emptying & 2065 \\
gastroparesis & 331175 \\
gastric & 234837 \\
stomach & 1 \\
Cajal interstitial cell & 82 \\
Interstitial cell of Cajal & 1827 \\
Cajal interstitial cells & 1827 \\
Interstitial cells of Cajal & 1 \\
\hline
\end{tabular}

\section{Results}

\section{Gastroparesis and Interstitial Cells of Cajal in Animal Models}

Animal models of delayed gastric emptying have been used for the assessment of the role of ICC in the pathophysiology of GP. Neuronal nitric oxide synthase-deficient $\left(\mathrm{nNOS}^{-/-}\right)$mice and diabetic animals (eg, Streptozotocin treated rats, nonobese diabetic [NOD] mice, and ob/ob mouse model of obesity) are well-known animal models of GP. ${ }^{19-22}$ The results observed in ICC deficient mice or rats were contradictory. They have been used both as a model of duodenogastric reflux based on the presence of a hypotensive pyloric sphincter, as well as delayed gastric emptying mimicking GP. ${ }^{19,23}$

Ultrastructural changes of ICC as well as ICC depletion have been observed in diabetic animal models. Two recent studies by Chen et $\mathrm{al}^{24,25}$ showed that diabetes induced by streptozotocin in rats delays gastric emptying, decreases contractions of the antral strips, and decreases ICC-IM, ICC-MP, and ICC-SM counts in the antrum. In addition, the long processes of ICC-IM were impaired and C-Kit positive cells had incomplete membranes, fractured and shorten processes, slender cell bodies, swollen mitochondria, disrupted cristaed and condensed chromatin. Moreover, significant apoptosis was observed in ICC-IM, ICCMP, and ICC-SM. ${ }^{24,25}$ The restoration of ICC counts as well as their morphology after electroacupuncture may explain the effects of this treatment strategy on gastric emptying in this animal model. $^{24,25}$ Mogami et al $^{26}$ also showed ICC depletion in the whole stomach and more prominently in the antrum, 8 weeks af- ter injecting streptozotocin to rats. In another study ICC were depleted in the proximal part of the stomach in diabetic rats. ${ }^{27}$ Similar to changes observed with electroacupuncture, ${ }^{24,25} \mathrm{mRNA}$ expression of KIT in the stomach tissue was increased after treatment with Curcumin, the main active component of the spice turmeric. ${ }^{27}$

Wang et $\mathrm{al}^{28}$ reported that the density of ICC-IM and ICC-SM was reduced by $46.4 \%$ and $26.7 \%$, respectively in the antrum of streptozotocin induced diabetic rats. In addition, Long et $\mathrm{al}^{29}$ showed depleted antral ICC and ultrastructural changes such as decreased number of gap junctions of ICC in the antrum and damaged ICC organelles of the diabetic rats. The mouse model of streptozotocin induced diabetes also presents with gastric ICC depletion. ${ }^{30}$

The NOD mice present with reduced motor neurotransmission, delayed gastric emptying, and impaired electrical pace-making. ICC are greatly reduced in their antrum, and the normal associations between these cells and enteric nerves are affected. $^{31}$

In genetically ICC depleted (Ws/Ws) rats, ICC loss is not always directly translated to delayed gastric emptying. Zhang and colleagues $^{23}$ showed that gastric emptying is delayed and ICC-IM are depleted in the antrum of Ws/Ws rats, suggesting a possible correlation between ICC count and gastric motor function, while some other studies reported pyloric incompetency and bile reflux in this same animal model. $19,32,33$

As discussed above, most of the animal studies have shown correlation between ICC especially in the antrum with GP, but studies on the pyloric ICC are scarce and controversial. Wang et $\mathrm{al}^{34}$ showed that ICC-MP is naturally depleted in the pylorus of mouse and rat and the slow waves are lost in this region. On the other hand, based on a study by Seki and Komuro, ${ }^{35}$ ICC are 
Table 2. Gastric Interstitial Cells of Cajal Count in the Animal Models of Gastroparesis

\begin{tabular}{llll}
\hline \multicolumn{1}{c}{ Study } & \multicolumn{1}{c}{ Animal model } & \multicolumn{1}{c}{ Gastric region } & \multicolumn{1}{c}{ ICC population } \\
\hline Chen et al $(2013)^{24,25}$ & Diabetic Rat (Streptozotocin) & Antrum & ICC-IM $(\downarrow)$, ICC-MP $(\downarrow)$ and ICC-SM $(\downarrow)$ \\
Mogami et al $(2013)^{26}$ & Diabetic Rat (Streptozotocin) & Whole stomach, antrum and body & ICC-IM $(\downarrow)$, ICC-MP $(\rightarrow)$ and ICC-SM $(\downarrow)$ \\
Jin et al $(2013)^{27}$ & Diabetic Rat (Streptozotocin) & Proximal Stomach & ICC $(\downarrow)$ \\
Wu et al $(2013)^{30}$ & Diabetic Mouse (Streptozotocin) & Antrum and body & ICC-IM $(\downarrow), \operatorname{ICC-MP~}(\downarrow)$ \\
Zhang et al $(2011)^{23}$ & Ws/Ws Rat & Antrum & ICC-IM $(\downarrow), \operatorname{ICC-MP~}(\rightarrow)$ \\
Wang et al $(2009)^{28}$ & Diabetic Rat (Streptozotocin) & Antrum & ICC-IM $(\downarrow), \operatorname{ICC-MP~}(\rightarrow)$ and ICC-SM $(\downarrow)$ \\
& & Fundus & ICC $(\rightarrow)$ \\
Long et al $(2004)^{29}$ & Diabetic Rat (Streptozotocin) & Antrum & ICC $(\downarrow)$ \\
Mitsui $(2003)^{48}$ & Ws/Ws Rat & Antrum & ICC-IM (not observed), ICC-MP $(\downarrow)$ and \\
Ordög $(2000)^{31}$ & NOD mouse & Antrum & $\operatorname{ICC-SM~}(\downarrow)$ \\
\hline
\end{tabular}

ICC, interstitial cells of Cajal; ICC-IM, intramuscular ICC; ICC-MP, ICC in myenteric plexus; ICC-SM, submucosal ICC; Ws/Ws rat, ICC depleted rat; NOD, nonobese diabetic; $\rightarrow$, no change; $\downarrow$, decreased.

densely distributed throughout the cardia, fundus, and the squamous epithelial portion of the corpus as well as the pylorus of mice.

Available data on the ICC count in the diabetic and genetical animal models of GP are summarized in Table 2.

\section{Gastroparesis and Interstitial Cells of Cajal in Human}

\section{Interstitial cells of Cajal in the gastric body}

Depletion of ICC in the gastric body has been shown in different studies. For example, O'Grady et $\mathrm{al}^{36}$ showed substantial ICC loss in the gastric body circular muscle of 9 gastroparetic patients (6 DM-GP and 3 IP-GP) compared to controls. In another study, the Gastroparesis Clinical Research Consortium (GpCRC) which consists of a network of 8 medical centers and one data coordinating center collaborating to perform research on GP, assessed full-thickness gastric body biopsies from 20 patients with ID-GP and 20 patients with DM-GP who were undergoing surgery for the placement of a gastric stimulator as well as 20 controls. ICC populations were significantly decreased in both diabetic and idiopathic gastroparetic groups compared to the controls, with no difference in ICC loss between diabetic and idiopathic GP. $^{16}$

In a further clinical investigation by the GpCRC, the ICC population was lower in the gastric body of diabetic and idiopathic patients but the depleted ICC count correlated with the rate of gastric emptying of an isotope labeled meal in only the diabetic gastroparetic subgroup. There were no differences between the individual symptoms including nausea, vomiting and bloat- ing as well as the GP cardinal symptom index score (GCSI) based on either low or normal gastric body ICC counts. ${ }^{15}$

Mazzone et $\mathrm{al}^{37}$ also showed fewer ICC in the gastric body smooth muscle in patients with diabetic GP compared to controls based on both C-Kit and ANO1 staining.

In a case report, 2 patients with DM-GP, one with well controlled diabetes and the other one with poorly controlled diabetes, ICC counts were compared. Interestingly, the well-controlled patient had a normal ICC count; however, ICC-IM were depleted in the gastric body of the poorly controlled patient. Both patients were severely symptomatic. The conclusion was the severity of GP could not be predicted by the status of the ICC population in these 2 patients. ${ }^{10}$ Another case report, also showed loss of ICC network in the fundus, body and antrum of a severe ID-GP patient. $^{38}$

Ultrastructural changes such as wrinkling of the nucleus, karyorrhexis, pyknosis, and heterochromatin as well as decreased cytoplasmic volume, diffuse swelling of the cytoplasm, and dilatation of the endoplasmic reticulum have also been described in the gastric ICC of diabetic patients compared to controls. ${ }^{39}$ In gastroparetic patients where the ICC count may not be different compared to the controls, the ultrastructure of ICC in the gastric body might be abnormal. Indeed, apoptotic features and defects in the connection between ICC and nerve endings, smooth muscle and other ICC are observed in GP. These changes are more prominent in IP-GP compared to DM-GP. ${ }^{40}$

\section{Interstitial cells of Cajal in the gastric antrum}

Iwasaki et $\mathrm{al}^{41}$ showed depletion of ICC, nNOS and substance $\mathrm{P}$ in the antrum of diabetic patients. 
In another study, full-thickness antral biopsies in 28 patients (14 diabetic and 14 idiopathic) with refractory GP undergoing surgical laparotomy for the placement of a gastric electric stimulator were compared to 8 controls who were undergoing gastric resection for other reasons. A significant reduction in the number of ICC in the myenteric plexus in both diabetic and idiopathic gastroparetic patients compared to controls was observed, although there was no significant difference in the number of ICC in the outer longitudinal and inner circular muscle layers. ${ }^{17}$

Our group studied 41 adult patients with refractory GP (34 diabetic, 5 idiopathic, and 2 postsurgical) who were referred for gastric electrical stimulation (GES) and 10 control patients who underwent gastric resection or gastrectomy for reasons other than GP. Full-thickness antral biopsies were stained for C-Kit and the number of ICC were analyzed. The number of ICC was depleted in 15 patients $(37 \%)$ and was normal in 26 patients $(63 \%)$. No difference was found between the baseline symptom severities in ICC normal versus ICC depleted group. However, electrogastrography showed that patients with depleted ICC had significantly less numbers of normal slow waves and more tachygastria compared to those with adequate ICC population. ICC count did not significantly correlate with etiology, age, gender, symptom severity of GP and gastric emptying. However, severely depleted ICC was associated with a poorer symptomatic response to GES. $^{18}$

Most recently, a study in 26 gastroparetic patients who were referred for the insertion of a gastric electric stimulator (18 diabetic and 8 idiopathic) showed antral ICC depletion in 11 patients (42\%), and a trend toward decreased gastric emptying of an isotope labeled solid meal in patients with lower ICC population $(P<0.07)^{42}$
Studies on human gastric ICC counts and GP are summarized in Table 3.

\section{Interstitial cells of Cajal in the gastric pylorus}

Studies on the pyloric ICC in GP are sparse. A recent preliminary study showed that ICC are depleted in the pyloric smooth muscles of $61 \%$ of both DM-GP and ID-GP patients who required a GES. ${ }^{43}$

\section{Discussion and Conclusion}

The animal studies consistently demonstrate that ICC are depleted in diabetic gastroparetic models. On the other hand, data on animals with genetically depleted ICC are contradictory in that ICC loss does not always accompany delayed gastric emptying. Interestingly, it appears that ICC loss and abnormal morphology may be reversed by treatment in animals.

In the human literature, although the quality and the quantity of the studies concerning the role of ICC in the pathogenesis of GP may vary; gastric ICC are depleted in up to $50 \%$ of patients with either ID-GP or DM-GP.

More specifically, in the human gastric body, decreased ICC population as well as ultrastructural changes of ICC have been observed and there was correlation between depleted ICC population and gastric emptying in diabetics.

In the antrum which is the site of major gastric contractility and trituration of food, there were correlations between the clinical findings and the ICC population (Fig. 2).

Another entity which should be discussed here is gastroparesis-like syndrome. A recent article on gastroparesis-like syndrome indicated that this syndrome is associated with both deple-

Table 3. Gastric Interstitial Cells of Cajal Count in Gastroparetic Patients Versus Controls

\begin{tabular}{|c|c|c|c|c|}
\hline Study & Type of Study & Type of Gastroparesis & Gastric region & ICC population \\
\hline O'Grady $\mathrm{G}$ et al $(2012)^{36}$ & Case-Control & IP-GP and DM-GP & Body & $\operatorname{ICC}(\downarrow)$ \\
\hline Grover et al $(2011,2012)^{15,16}$ & Case-Control & IP-GP and DM-GP & Body & $\operatorname{ICC}(\downarrow)$ \\
\hline Mazzone et al (2011) & Case-Control & DM-GP & Body & $\operatorname{ICC}(\downarrow)$ \\
\hline Pasricha et al $(2008)^{10}$ & Case Report & DM-GP & Body & $\begin{array}{c}\mathrm{ICC}(\downarrow) \text { in a case with } \\
\text { uncontrolled diabetes }\end{array}$ \\
\hline Battaglia et al $(2006)^{38}$ & Case Report & IP-GP & Fundus, body and antrum & $\operatorname{ICC}(\downarrow)$ \\
\hline Zárate et al $(2003)^{49}$ & Case Report & IP-GP & Body, antrum, and pylorus & $\operatorname{ICC}(\downarrow)$ \\
\hline Harberson et al $(2010)^{17}$ & Case-Control & IP-GP and DM-GP & Antrum & $\operatorname{ICC}(\downarrow)$ \\
\hline Lin et al $(2010)^{18}$ & Case-Control & IP-GP and DM-GP & Antrum & $\operatorname{ICC}(\downarrow)$ \\
\hline Iwasaki et al $(2006)^{41}$ & Case-Control & DM-GP & Antrum & $\operatorname{ICC}(\downarrow)$ \\
\hline Forster et al $(2005)^{50}$ & Case-Control & IP-GP and DM-GP & Antrum & $\operatorname{ICC}(\downarrow)$ \\
\hline
\end{tabular}

ICC, interstitial cells of Cajal; DM-GP, diabetic gastroparesis; IP-GP, idiopathic gastroparesis; $\downarrow$, decreased. 

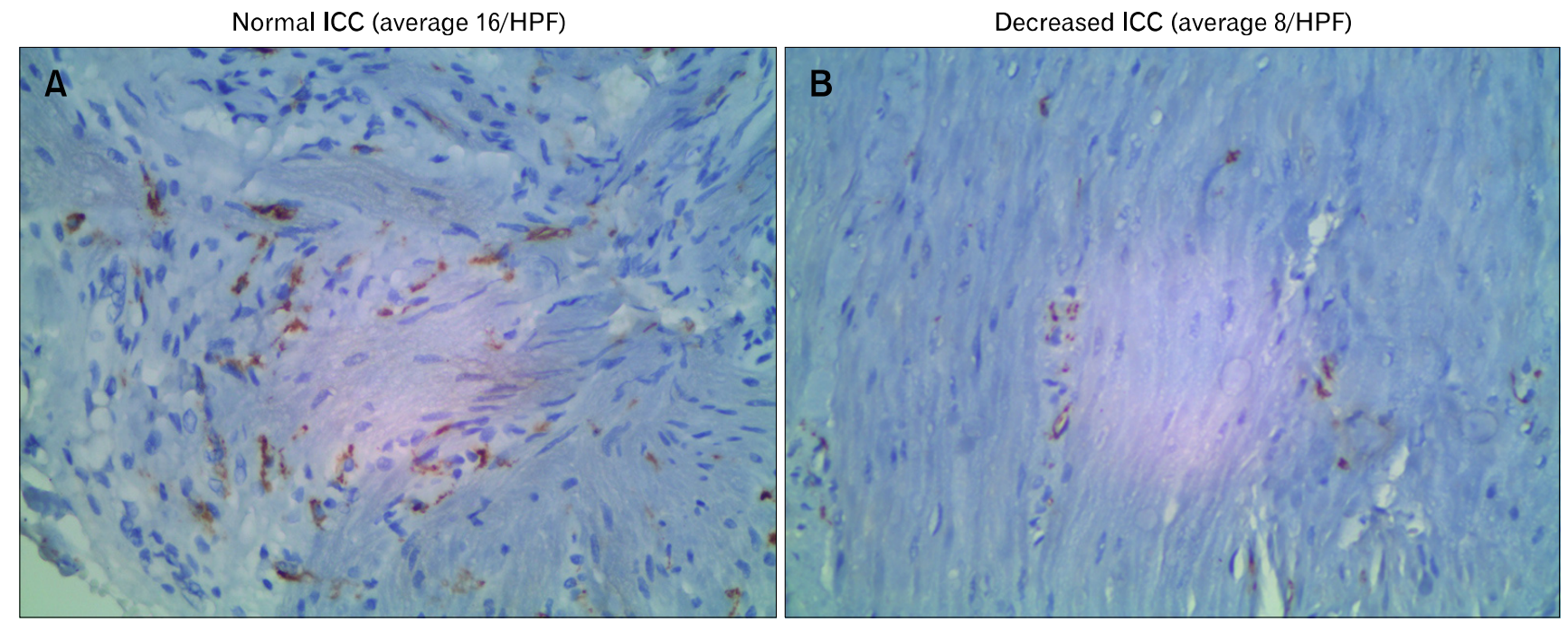

Figure 2. Antral muscularis propria immunostained with C-Kit primary antibody in a non-gastroparetic (A) and a gastroparetic patient (B). The images were taken at 160 magnification of formalin preserved full-thickness $1 \mathrm{~cm}^{2}$ surgically obtained gastric biopsies. Interstitial cells of Cajal (ICC) are spindle-shaped brown elements on the image. (A) Normal numbers of ICC which is $20 \pm 10$ (mean $\pm 2 \mathrm{SD}$ ) cells per high powered field (HPF). (B) Depleted numbers of ICC (less than 10 cells/HPF).

tion and mild ultrastructural abnormalities of the ICC in the stomach. ${ }^{44}$ The hypothesis that gastroparesis like syndrome is a part of a spectrum of the same condition as GP needs to be addressed in future studies. ${ }^{45}$

Whether ICC can be used as the predictor of therapeutic response in GP is not yet clear. Future studies should address which ICC subtypes are the key players in the development of $\mathrm{GP}$ as well as the mechanisms whereby ICC are affected. Maybe, larger animals would be more helpful in differentiating and studying ICC counts and morphology based on different gastric segments. In addition, animal models should emphasize the effect of gender in the development of GP, since $80 \%$ of gastroparetic patients are females. Future animal studies should also include drug induced GP as a model (ie, Is the medication toxic to the ICC?) vs post-viral GP and the progressive injury model of diabetes.

Whether ultrastructural and functional changes of ICC are more important than ICC count needs further investigation. Moreover, future studies should address whether ICC loss is an absolute finding, or is an indicative of a more generalized neuropathic process. Another important observation is whether ICC-opathy is a cause, a consequence or an epiphenomenon accompanying GP.

The current literature for the analysis of ICC is limited to patients with severe symptoms who underwent surgery (eg, insertion of electrical stimulation or J-tube). It is not clear whether ICC counts and ultrastructure are also changed in patients with mild or moderate GP since in these patients gastric full thickness biopsies have not been studied. Moreover, the importance of pyloric ICC in the development of GP needs more of focus in future multi-center studies with adequate sample size.

Future research in humans will benefit by a recent breakthrough in obtaining nonsurgical gastric biopsies through percutaneous endoscopically assisted transenteric full-thickness gastric biopsy, ${ }^{46}$ or antral muscularis propria biopsies utilizing endoscopic ultrasound guidance. ${ }^{47}$ This ability to have nonsurgical access to smooth muscles will facilitate better understanding of ICC in different clinical settings including their role in the development of GP and as the predictors of response to medical therapies. For now, the body of evidence we have summarized supports an overall role for ICC in the pathophysiology of GP.

\section{Acknowledgements}

We thank Dr. Alireza Torabi, Department of Pathology, Texas Tech University Health Sciences Center who kindly provided the pathology slides presented in this review article.

\section{References}

1. Parkman HP, McCallum RW. Gastroparesis: pathophysiology, presentation, and treatment. New York: Humana Press 2012:xvi, 
2012:422.

2. Jung HK, Choung RS, Locke GR 3rd, et al. The incidence, prevalence, and outcomes of patients with gastroparesis in Olmsted County, Minnesota, from 1996 to 2006. Gastroenterology 2009;136: 1225-1233.

3. Choung RS, Locke GR 3rd, Schleck CD, Zinsmeister AR, Melton LJ 3rd, Talley NJ. Risk of gastroparesis in subjects with type 1 and 2 diabetes in the general population. Am J Gastroenterol 2012;107: 82-88.

4. Kaplan LM, McCallum RW, Koch KL, Sederman R, Henderson B. High prevalence and underdiagnosis of gastroparesis symptoms among patients with type 1 and type 2 diabetes mellitus. Gastroenterology 2013;144:S107.

5. Bharucha AE. Epidemiology and natural history of gastroparesis. Gastroenterol Clin North Am 2015;44:9-19.

6. Wang YR, Fisher RS, Parkman HP. Gastroparesis-related hospitalizations in the United States: trends, characteristics, and outcomes, 1995-2004. Am J Gastroenterol 2008;103:313-322.

7. Huizinga JD, Chen JH. Interstitial cells of Cajal: update on basic and clinical science. Curr Gastroenterol Rep 2014;16:363.

8. Takaki M. Gut pacemaker cells: the interstitial cells of Cajal (ICC). J Smooth Muscle Res 2003;39:137-161.

9. Kito $\mathrm{Y}$. The functional role of intramuscular interstitial cells of Cajal in the stomach. J Smooth Muscle Res 2011;47:47-53.

10. Pasricha PJ, Pehlivanov ND, Gomez G, Vittal H, Lurken MS, Farrugia G. Changes in the gastric enteric nervous system and muscle: a case report on two patients with diabetic gastroparesis. BMC Gastroenterol 2008;8:21.

11. Sanders KM, Ordög T, Koh SD, Torihashi S, Ward SM. Development and plasticity of interstitial cells of Cajal. Neurogastroenterol Motil 1999;11:311-338.

12. Kashyap P, Gomez-Pinilla PJ, Pozo MJ, et al. Immunoreactivity for Ano1 detects depletion of Kit-positive interstitial cells of Cajal in patients with slow transit constipation. Neurogastroenterol Motil 2011; 23:760-765.

13. Bernardini N, Segnani C, Ippolito C, et al. Immunohistochemical analysis of myenteric ganglia and interstitial cells of Cajal in ulcerative colitis. J Cell Mol Med 2012;16:318-327.

14. Wang XY, Zarate N, Soderholm JD, Bourgeois JM, Liu LW, Huizinga JD. Ultrastructural injury to interstitial cells of Cajal and communication with mast cells in Crohn's disease. Neurogastroenterol Motil 2007; 19:349-364.

15. Grover M, Bernard CE, Pasricha PJ, et al. Clinical-histological associations in gastroparesis: results from the Gastroparesis Clinical Research Consortium. Neurogastroenterol Motil 2012;24:531-539, e249.

16. Grover M, Farrugia G, Lurken MS, et al. Cellular changes in diabetic and idiopathic gastroparesis. Gastroenterology 2011;140:1575-1585,e8.

17. Harberson J, Thomas RM, Harbison SP, Parkman HP. Gastric neuromuscular pathology in gastroparesis: analysis of full-thickness antral biopsies. Dig Dis Sci 2010;55:359-370.

18. Lin Z, Sarosiek I, Forster J, Damjanov I, Hou Q, McCallum RW. Association of the status of interstitial cells of Cajal and electrogastrogram parameters, gastric emptying and symptoms in patients with gastroparesis. Neurogastroenterol Motil 2010;22:56-61, e10.

19. Sivarao DV, Mashimo H, Goyal RK. Pyloric sphincter dysfunction in $\mathrm{nNOS}^{-/-}$and W/Wv mutant mice: animal models of gastroparesis and duodenogastric reflux. Gastroenterology 2008;135:1258-1266.

20. Choi KM, Gibbons SJ, Nguyen TV, et al. Heme oxygenase-1 protects interstitial cells of Cajal from oxidative stress and reverses diabetic gastroparesis. Gastroenterology 2008;135:2055-2064, e1-e2.

21. Bhetwal BP, An C, Baker SA, Lyon KL, Perrino BA. Impaired contractile responses and altered expression and phosphorylation of $\mathrm{Ca}^{2+}$ sensitization proteins in gastric antrum smooth muscles from ob/ob mice. J Muscle Res Cell Motil 2013;34:137-149.

22. Huang PL, Dawson TM, Bredt DS, Snyder SH, Fishman MC. Targeted disruption of the neuronal nitric oxide synthase gene. Cell 1993;75:1273-1286.

23. Zhang RX, Wang XY, Chen D, Huizinga JD. Role of interstitial cells of Cajal in the generation and modulation of motor activity induced by cholinergic neurotransmission in the stomach. Neurogastroenterol Motil 2011;23:e356-e371.

24. Chen Y, Xu J, Liu S, Hou X. Electroacupuncture at ST36 increases contraction of the gastric antrum and improves the SCF/c-kit pathway in diabetic rats. Am J Chin Med 2013;41:1233-1249.

25. Chen Y, Xu JJ, Liu S, Hou XH. Electroacupuncture at ST36 ameliorates gastric emptying and rescues networks of interstitial cells of Cajal in the stomach of diabetic rats. PLoS One 2013;8:e83904.

26. Mogami S, Suzuki H, Tsugawa H, Fukuhara S, Hibi T. Impaired heme oxygenase- 1 induction in the gastric antrum induces disruption of the interstitial cells of Cajal network in a rat model of streptozotocin-induced diabetes. Neurogastroenterol Motil 2013;25:609-e465.

27. Jin QH, Shen HX, Wang H, Shou QY, Liu Q. Curcumin improves expression of $\mathrm{SCF} / \mathrm{c}$-kit through attenuating oxidative stress and $\mathrm{NF}$-kappaB activation in gastric tissues of diabetic gastroparesis rats. Diabetol Metab Syndr 2013;5:12.

28. Wang XY, Huizinga JD, Diamond J, Liu LW. Loss of intramuscular and submuscular interstitial cells of Cajal and associated enteric nerves is related to decreased gastric emptying in streptozotocin-induced diabetes. Neurogastroenterol Motil 2009;21:1095-e1092.

29. Long QL, Fang DC, Shi HT, Luo YH. Gastro-electric dysrhythm and lack of gastric interstitial cells of cajal. World J Gastroenterol 2004;10:1227-1230.

30. Wu YS, Lu HL, Huang X, et al. Diabetes-induced loss of gastric ICC accompanied by up-regulation of natriuretic peptide signaling pathways in STZ-induced diabetic mice. Peptides 2013;40:104-111.

31. Ordog T, Takayama I, Cheung WK, Ward SM, Sanders KM. Remodeling of networks of interstitial cells of Cajal in a murine model of diabetic gastroparesis. Diabetes 2000;49:1731-1739.

32. Nakama A, Hirota S, Okazaki T, et al. Disturbed pyloric motility in Ws/Ws mutant rats due to deficiency of c-kit-expressing interstitial cells of Cajal. Pathol Int 1998;48:843-849.

33. Isozaki K, Hirota $\mathrm{S}$, Nakama A, et al. Disturbed intestinal movement, bile reflux to the stomach, and deficiency of c-kit-expressing cells in Ws/Ws mutant rats. Gastroenterology 1995;109:456-464.

34. Wang XY, Lammers WJ, Bercik P, Huizinga JD. Lack of pyloric interstitial cells of Cajal explains distinct peristaltic motor patterns in stomach and small intestine. Am J Physiol Gastrointest Liver Physiol 2005;289:G539-549.

35. Seki K, Komuro T. Distribution of interstitial cells of Cajal and gap junction protein, $\mathrm{Cx} 43$ in the stomach of wild-type and $\mathrm{W} / \mathrm{Wv} \mathrm{mu}$ tant mice. Anat Embryol (Berl) 2002;206:57-65. 
36. O'Grady G, Angeli TR, Du P, et al. Abnormal initiation and conduction of slow-wave activity in gastroparesis, defined by high-resolution electrical mapping. Gastroenterology 2012;143:589-598, e1-e3.

37. Mazzone A, Bernard CE, Strege PR, et al. Altered expression of Ano1 variants in human diabetic gastroparesis. J Biol Chem 2011; 286:13393-13403.

38. Battaglia E, Bassotti G, Bellone G, et al. Loss of interstitial cells of Cajal network in severe idiopathic gastroparesis. World J Gastroenterol 2006;12:6172-6177.

39. Kim ER, Kim KM, Lee JY, et al. The clue of Interstitial Cell of Cajalopathy (ICCpathy) in human diabetic gastropathy: the ultrastructural and electrical clues of ICCpathy in human diabetic gastropathy. Exp Toxicol Pathol 2012;64:521-526.

40. Faussone-Pellegrini MS, Grover M, Pasricha PJ, et al. Ultrastructural differences between diabetic and idiopathic gastroparesis. J Cell Mol Med 2012;16:1573-1581.

41. Iwasaki H, Kajimura M, Osawa S, et al. A deficiency of gastric interstitial cells of Cajal accompanied by decreased expression of neuronal nitric oxide synthase and substance $\mathrm{P}$ in patients with type 2 diabetes mellitus. J Gastroenterol 2006;41:1076-1087.

42. McCallum RW, Elhanafi S, Saadi M, Sarosiek I, Davis BI, Torabi AR. Relationship of gastric emptying with numbers of interstitial cells of Cajal in antral muscularis propria of gastropasis patients. Gastroenterology 2015;148(suppl 1):S517.

43. Elhanafi S, Torabi AR, Sarosiek I, Davis BI, RW. M. Analysis of Interstitial cells of Cajal in pyloric smooth muscle in gastroparesis patients. Gastroenterology 2015;148(suppl 1):S513.
44. Angeli TR, Cheng LK, Du P, et al. Loss of interstitial cells of Cajal and patterns of gastric dysrhythmia in patients with chronic unexplained nausea and vomiting. Gastroenterology 2015;149:56-66, e5.

45. Bashashati M, McCallum RW. Motility: is 'ICC-opathy' present in gastroparesis-like syndrome? Nat Rev Gastroenterol Hepatol 2015; 12:375-376.

46. Andrews CN, Mintchev P, Neshev E, et al. Percutaneous endoscopically assisted transenteric full-thickness gastric biopsy: initial experience in humans. Gastrointest Endosc 2011;73:949-954.

47. Othman MO, Davis B, Saroseik I, Torabi A, McCallum RW. EUS-guided FNA biopsy of the muscularis propria of the antrum in patients with gastroparesis is feasible and safe. Gastrointest Endosc Published Online First: 26 Aug 2015. doi: 10.1016/j.gie.2015.06. 056.

48. Mitsui R, Komuro T. Distribution and ultrastructure of interstitial cells of Cajal in the gastric antrum of wild-type and Ws/Ws rats. Anat Embryol (Berl) 2003;206:453-460.

49. Zarate N, Mearin F, Wang XY, Hewlett B, Huizinga JD, Malagelada JR. Severe idiopathic gastroparesis due to neuronal and interstitial cells of Cajal degeneration: pathological findings and management. Gut 2003;52:966-970.

50. Forster J, Damjanov I, Lin Z, Sarosiek I, Wetzel P, McCallum RW. Absence of the interstitial cells of Cajal in patients with gastroparesis and correlation with clinical findings. J Gastrointest Surg $2005 ; 9: 102-108$. 